\title{
FGF, BMP, and TGF $\beta$ signaling together control human embryonic stem cell fates
}

\author{
Ren-He $\mathrm{Xu}^{1}$ \\ ${ }^{1}$ Department of Genetics and Developmental Biology, University of Connecticut Health Center, Farmington, CT., USA
}

Although both mouse and human embryonic stem cells (hESCs) can be maintained on fibroblast feeder cells, extrinsic cues identified to sustain their self-renewal are different. Leukemia inhibitory factor and bone morphogenetic proteins (BMPs), members of the TGF $\beta$ super-family, are sufficient to maintain self-renewal of mouse, but not human, ES cells. Instead, we and others have found that self-renewal of hESCs is promoted by FGF and TGFß/Activin signaling, and their differentiation is promoted by BMP signaling. Using a defined medium, we have further shown that both TGF $\beta$ and FGF signals synergize to inhibit BMP signaling, sustain expression of pluripotency-associated genes, and promote long-term undifferentiated proliferation of hESCs. We further characterized the molecular mechanisms that link these signaling pathways with maintenance of pluripotency in the cells. Together we demonstrate that FGF, BMP, and TGF $\beta$ signaling are three driving forces that control the hESC fates.

Cell Research (2008) 18:s29. doi: 10.1038/cr.2008.119; published online 4 August 2008

Correspondence: Ren-He Xu

Ren-He $\mathrm{Xu}, \mathrm{MD} / \mathrm{PhD}$, is the Director of University of Connecticut Stem Cell Core. Dr $\mathrm{Xu}$ received MD degree from Hengyang Medical College (currently South China University) and a PhD degree in developmental biology from University of Tokyo. He is an Associate Professor of Genetics and Developmental Biology, and a joint faculty of the Center for Regenerative Biology, University of Connecticut. He received an Outstanding Science Achievement Award from the NCIFCRDC, NIH, and was an Honoree of 2007 Connecticut State Registry and Manual. Dr Xu's research focuses on embryonic stem (ES) cells to understand mechanisms for their self-renewal and differentiation and BMP/TGF $\beta$ signaling. Please visit his websites for more details: Lab: http://genetics.uchc.edu/faculty/ xu.htm, and Stem Cell Core: http://genetics.uchc.edu/StemCell/index.htm. 